\title{
Fundamentos Conceituais para uma Sociologia da Dogmática Jurídica ${ }^{7}$
}

\author{
Cristiano Estrela da Silva
}

\section{RESUMO}

A presente dissertação objetiva analisar uma noção jurídica, a de dognática jurídica, sob um ponto de vista sociológico. Parte-se do estabelecimento de un marco teórico específico, Max Weber, e de uma reflexão eminentemente conceitual para, em un segundo momento, compreender a dogmática jurídica em um contexto de racionalização material do direito. Busca-se, neste contexto, captar o sentido da atividade dogmática tanto na elaboração de conceitos em abstrato quanto na solução de casos concretos.

${ }^{3}$ A Banca Examinadora foi composta pelo Professor Doutor Femando Atria, Professor da Universidade Adolfo Ibanez - Chile e Doutor em Direito pela Universidade Edimburgo, EU - Grä-Bretanha, pelo Professor Doutor Luís Fernando Barzotto, Professor Adjunto I da Universidade Federal do Rio Grande do Sul e Doutor em Direito pela Universidade de São Paulo, e pelo Professor Doutor João Maurício Leitão Adeodato, Professor Titular da Universidade Federal de Pernanbuco e Doutor em Direito pela Universidade de São Paulo. A referida defesa foi presidida pelo Professor Doutor Cláudio Fortunato Michelon Júnior, Professor Adjunto I da Universidade Federal do Rio Grande do Sul, Doutor em Direto pela Universidade Edimburgo, EU - Grä-Bretanha, e orientador do teferido trabalho. 